\title{
Analisis Displacement dan Tegangan von Mises Terhadap Chassis Mobil Listrik Gentayu
}

\author{
Rifky Ismail*, Munadi, Zakki Kurniawan Ahmad, Athanasius Priharyoto Bayuseno \\ Departemen Teknik Mesin, Fakultas Teknik, Universitas Diponegoro \\ Jl. Prof. Sudharto Kampus UNDIP Tembalang Semarang 50275 \\ *E-mail: r_ismail@undip.ac.id
}

\begin{abstract}
The use of electric cars is increasingly rated positively due to its lower air pollution and its simpler machine construction. Diponegoro University currently has a two-passenger electric car platform, Gentayu, which has been developed in the past few years. In the development of the Gentayu electric car, a chassis frame is needed to support all vehicle loads. The chassis must have the good strength to hold the load and able to distribute the load properly. This study aims to analyze the selection of the Gentayu electric car chassis using the finite element method and provide material recommendations for the Gentayu electric car chassis. This study has two stages, namely, designing the Gentayu electric car model using the Solidwork 2017 application and simulating the finite element method (FEM) using ABAQUS software. In the simulation phase, FEM is carried out by importing the chassis models from the Solidwork application. The material used in this simulation is alloy steel, aluminum AISI 6061, and carbon fiber. The results obtained from this study are von Mises stress and displacement. The highest von Mises stress is found in carbon fiber material, 200,82 MPa and the highest displacement is found in AISI 6061 aluminum, 5,83 mm. In general, the three types of material selected in the simulation provide safe value. Alloy steel material has advantages in terms of cost and ease of welding with the body of an electric car.
\end{abstract}

Kata kunci: analisis tegangan, analisis displacement, chassis, FEM

\section{Abstrak}

Penggunaan mobil listrik semakin dinilai positif karena tidak menimbulkan polusi udara secara langung dan memiliki kontruksi mesin yang lebih sederhana. Universitas Diponegoro saat ini memiliki mobil listrik platform 2 penumpang Gentayu yang telah dikembangkan dalam beberapa tahun terakhir. Pada pengembangan mobil listrik Gentayu ini dibutuhkan sebuah rangka chassis yang berfungsi sebagai penopang semua beban kendaraan. Chassis ini harus memiliki kekuatan untuk menahan beban dan dapat mendistribusikan beban dengan baik. Penelitian ini bertujuan untuk menganalisis pilihan chassis mobil listrik Gentayu menggunakan metode elemen hingga dan memberikan rekomendasi material untuk chassis mobil listrik Gentayu. Penelitian ini mempunyai 2 tahapan inti yaitu, melakukan perancangan/desain model mobil listik Gentayu menggunakan aplikasi Solidwork 2017 dan simulasi finite element method (FEM) menggunakan software ABAQUS. Pada tahap simulasi FEM dilakukan proses import model chassis dari aplikasi Solidwork. Material yang digunakan dalam simulasi ini adalah alloy steel, alumunium AISI 6061, dan carbon fiber. Hasil yang didapat dari penelitian ini adalah tegangan von Mises dan displacement. Tegangan von Mises tertinggi berada pada material carbon fiber yaitu 200,82 MPa dan displacement tertinggi berada pada material alumunium AISI 6061 yaitu 5,83 $\mathrm{mm}$. Secara umum ketiga jenis material yang dipilih pada simulasi memberikan nilai yang masih aman secara teknis. Material alloy steel memiliki keunggulan dari aspek biaya dan kemudahan dalam proses pengelasan dengan body mobil listrik.

Kata kunci: analisis tegangan, analisis displacement, chassis, FEM

\section{Pendahuluan}

Penggunaan mobil listrik semakin dinilai positif karena tidak menimbulkan polusi udara secara langung dan memiliki kontruksi mesin yang lebih sederhana. Universitas Diponegoro saat ini memiliki mobil listrik platform 2 penumpang Gentayu yang telah dikembangkan dalam beberapa tahun terakhir. Pada pengembangan mobil listrik Gentayu ini dibutuhkan sebuah rangka chassis yang berfungsi sebagai penopang semua beban kendaraan. Chassis ini harus memiliki kekuatan untuk menahan beban dan dapat mendistribusikan beban dengan baik [1].

Chassis juga berfungsi untuk menjaga agar mobil tetap stabil, kaku dan tidak mengalami pembebanan yang berlebihan. Apabila pembebanan yang diberikan pada material berlebihan, material dapat berdeformasi melebihi nilai ambang tegangan luluh [2]. Analisis tegangan (stress analysis) penting dalam mengetahui tegangan, deformasi kelelahan (fatigue) dan life prediction yang dialami komponen untuk menentukan titik stress tertinggi yang biasa dikenal sebagai titik kritis yang mengawali kegagalan. Titik kritis ini adalah salah satu faktor yang dapat menyebabkan 
fatigue failure. Besarnya tegangan kerja saat chasis menerima beban dapat digunakan untuk memprediksi masa pakai chassis. Lokasi titik tekanan kritis sangat penting sehingga pemasangan komponen seperti mesin, suspensi, transmisi dan banyak lagi dapat ditentukan dan dioptimalkan.

Metode Elemen Hingga (FEM) adalah salah satu metode untuk menemukan titik kritis [3]. Chassis yang ada saat ini biasanya terbuat dari steel namun karena dirasa massanya terlalu berat maka mulai banyak berkembang chassis dengan bahan dasar aluminium dan carbon fiber yang mempunyai massa jenis lebih ringan dibandingkan steel [4]. Untuk itu, Analisis perlu dilakukan menggunakan metode elemen hingga terhadap beberapa variasi material yang digunakan untuk chassis dan pertimbangan beberapa aspek lain.

Penelitian sebelumnya mengenai chassis telah dilakukan terhadap mobil listrik Gentayu Undip seperti Makhrojan, dkk. [5] yang membahas tentang simulasi chassis menggunakan metode elemen hingga dengan variasi ketebalan plat bodi mobil. Selanjutnya Makhrojan, dkk. [6] juga melanjutkan penelitian tentang simulasi pada chassis menggunakan metode elemen hingga dengan variasi pembebanan pada mobil listrik. Selain itu, pada penelitian lainnya yang dilakukan oleh Budi, dkk. [7] membahas tentang fungsi suspensi pegas depan mobil listrik menggunakan jenis Mc Pherson untuk mengendalikan stabilitas kendaraan dan meningkatkan kenyamanan berkendara.

Berikutnya, beberapa penelitian lain yang membahas tentang mobil listrik Gentayu juga dilakukan oleh Setiyawan, dkk [8] yang melakukan penelitian tentang analisa konsumsi baterai dengan berbagai variasi jenis lampu dan beban konsumsi wiper saat hujan pada obil listrik yang nantinya akan digunakan untuk memberikan rekomendiasi sistem penerangan yang paling efisien untuk mobil listrik. Rifano, dkk. [9] membahas tentang fungsi desain kursi pengemudi untuk mobil listrik menggunakan analisa ergonomik yang diharapkan mampu memberikan rekomendasi berdasarkan studi tentang postur pengemudi Indonesia di city car listrik dengan menggunakan goniometer sebagai alat ukur posisi duduk pengemudi.

Pada mobil listrik, penempatan posisi baterai berperan vital karena baterai yang digunakan pada mobil listrik ini memberikan beban yang sangat besar, selain beban pengemudi dan penumpang. Dengan adanya variasi dari jenis material chassis yang ada, lokasi penempatan dari baterai dapat mempengaruhi nilai tegangan dan deformasi yang muncul pada chassis. Untuk itu, penelitian ini membahas tentang pemilihan lokasi baterai pada mobil listrik Gentayu dengan mempertimbangkan jenis material yang dapat dipilih untuk chassis.

\section{Metode Penelitian}

\subsection{Software}

ABAQUS adalah sebuah perangkat lunak untuk program simulasi engineering yang menggunakan prinsip dasar metode elemen hingga sehingga dapat memecahkan masalah mulai dari analisis linier yang relatif sederhana sampai simulasi nonlinier yang lebih rumit. Program ini berfungsi sebagai metode analisis model yang akan kita analisis kekuatannya. Seperti kebanyakan program komputer yang banyak tersedia di pasaran, ABAQUS mempunyai fasilitas $\mathrm{CAD} / \mathrm{CAM} / \mathrm{CAE}$ yang bisa difungsikan sebagai program analisis elastis dan plastis.

Sebagai bahan dalam penelitian ini adalah mobil listrik Gentayu, namaun hanya difokuskan pada chassisnya yang kemudian diberi beban. Dengan pembebanan aki berjumlah 6 buah dengan masing masing aki mempunyai massa $18 \mathrm{~kg}$ dan 2 penumpang dengan total massa $200 \mathrm{~kg}$. Gambar 1 menunjukan desain mobil listrik Gentayu menggunakan aplikasi Solidwork.

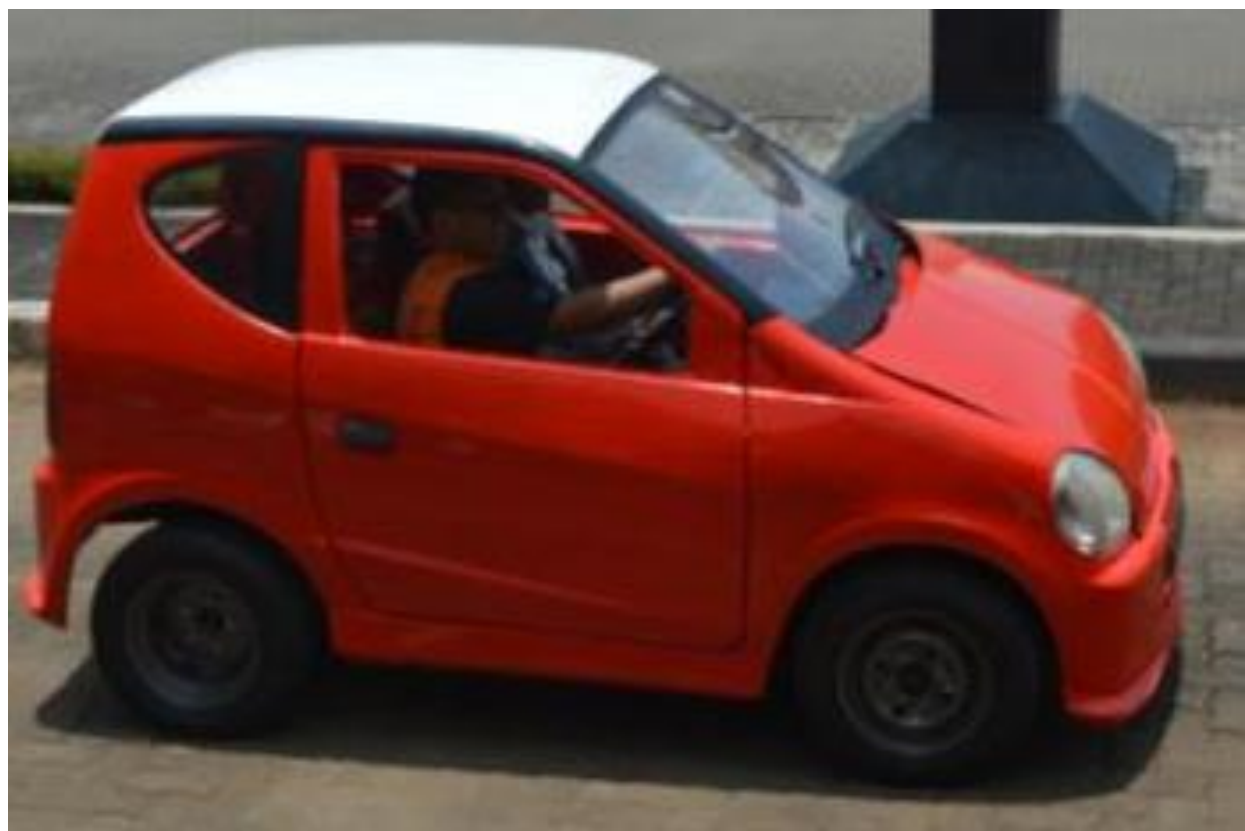

Gambar 1. Mobil listrik Gentayu. 


\subsection{Material yang Digunakan}

Dalam penelitian yang akan dilakukan penulis telah memilih 3 variasi material yang digunakan. Kemudian akan dianalisis dan dibandingkan nilai dari von Mises dan displacement dari chassis mobil listrik Gentayu. Berikut mechanical properties dari ketiga material dapat dilihat pada Tabel 1 - 3 .

Tabel 1 Mechanical properties alloy steel berdasarkan penelitian sebelumnya [5].

\begin{tabular}{cc}
\hline Mechanical Properties & Nilai \\
\hline Density & $785 \mathrm{ton} / \mathrm{m}^{3}$ \\
Tensile Strength, Ultimate & $460 \mathrm{MPa}$ \\
Tensile Strength, Yield & $250 \mathrm{MPa}$ \\
Modulus of Elasticity & $207000 \mathrm{MPa}$ \\
Poisson's Ratio & 0,3 \\
Plastic Strain at UTS & 0,35 \\
\hline
\end{tabular}

Tabel 2 Mechanical properties aluminium 6061 [10].

\begin{tabular}{cc}
\hline Mechanical Properties & Nilai \\
\hline Density & 270 ton $/ \mathrm{m}^{3}$ \\
Ultimate Tensile Strength & $310 \mathrm{MPa}$ \\
Tensile Yield Strength & $276 \mathrm{MPa}$ \\
Modulus of Elasticity & $68900 \mathrm{MPa}$ \\
Poisson's Ratio & 0,33 \\
Shear Modulus & $26000 \mathrm{MPa}$ \\
\hline
\end{tabular}

Tabel 3 Mechanical properties carbon fiber [11].

\begin{tabular}{cc}
\hline Mechanical Properties & Nilai \\
Density & $1,6 \mathrm{ton} / \mathrm{m}^{3}$ \\
Ultimate Tensile Strength & $500 \mathrm{MPa}$ \\
Tensile Yield Strength & $410 \mathrm{MPa}$ \\
Modulus of Elasticity & $235.000 \mathrm{MPa}$ \\
Poisson's Ratio & 0,25 \\
Shear Modulus & $49.000 \mathrm{MPa}$ \\
\hline
\end{tabular}

\subsection{Pembebanan}

Pada kondisi mobil listrik tanpa baterai dan tanpa penumpang, distribusi beban dari 4 roda saat ditimbang di alat ukur adalah sebagai berikut: roda depan kanan dan kiri masing-masing $150 \mathrm{~kg}$, roda belakang kiri $110 \mathrm{~kg}$ dan roda belakang kanan adalah 100kg. Pada penelitian ini, beban tambahan yang diberikan adalah beban 2 penumpang dengan massa asumsi maksimal $100 \mathrm{~kg}$ dan beban baterai basah yang digunakan pada mobil listrik ini dengan nilai percepatan gravitasi $9,8 \mathrm{~m} / \mathrm{s}^{2}$. Setiap baterai memiliki massa $18 \mathrm{~kg}$ dan berjumlah 6 maka untuk massa total massa baterai adalah $108 \mathrm{~kg}$. Pemberian beban dibedakan menjadi 2 kasus yaitu : kasus 1 dan kasus 2 dapat dilihat pada Tabel 4. Sedangkan untuk diagram benda bebas dapat dilihat pada Gambar 3.

Tabel 4. Keterangan pada setiap kasus pembebanan

\section{Variasi Pembebanan Keterangan}

Kasus $1 \quad$ Aki terletak di depan dengan 2 penumpang, total massa penumpang $200 \mathrm{~kg}$.

Kasus 2 Aki terletak di belakang dengan 2 penumpang, total massa penumpang $200 \mathrm{~kg}$.

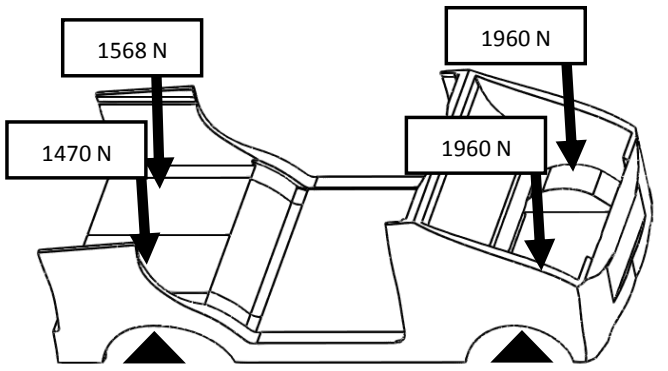

(a)

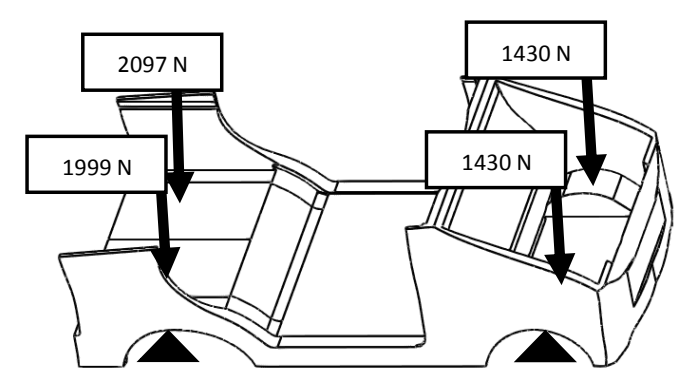

(b) 


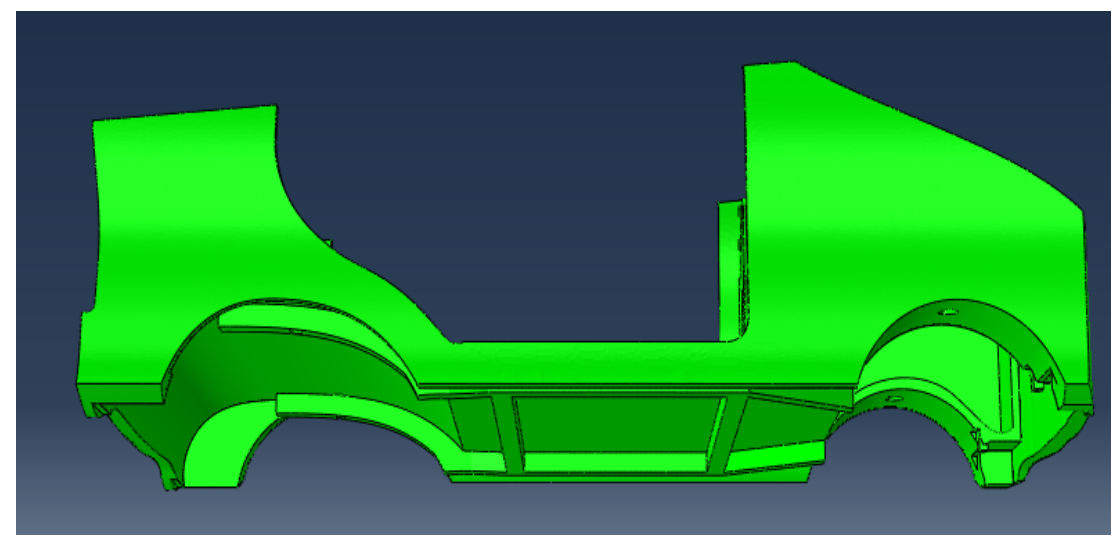

(c)

Gambar 3. Variasi pembebanan pada chassis (a) kasus 1, (b) kasus 2 dan (c) adalah posisi chassis di bawah plat body bagian bawah.

Mesh yang digunakan dalam penelitian ini menggunakan jenis tetrahedral yang secara automatic di-create oleh ABAQUS dan jumlah element yang digunakan adalah 1,03 juta elemen dengan jumlah nodal sejumlah 1,57 juta. Penggunaan jumlah ini telah dilakukan validasi sebelumnya dan mesh yang terpilih menggunakan mesh 11 yang disediakan oleh ABAQUS. Validasi ini melibatkan pemilihan beberapa jenis ukuran mulai dari ukuran mesh 9 hingga 13.

Setelah mendapatkan hasil dari simulasi FEM dilanjutkan dengan menghitung safety factor. Karena keamanan suatu desain dapat ditunjukan dengan suatu nilai yang disebut faktor keamanan atau safety factor. Nilai dari safety factor dipengaruhi oleh tegangan yang terjadi pada kontruksi. Untuk batas keamaan chassis nilainya lebih dari 1. Jika nilai safety factor material akan mengalami deformasi plastis yang nantinya akan menjadikan failure.

\section{Hasil dan Pembahasan}

\subsection{Hasil Simulasi Pada Chassis Mobil Listrik Gentayu}
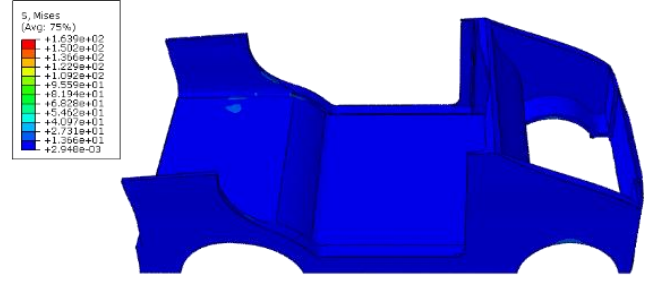

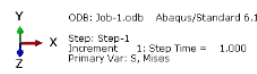

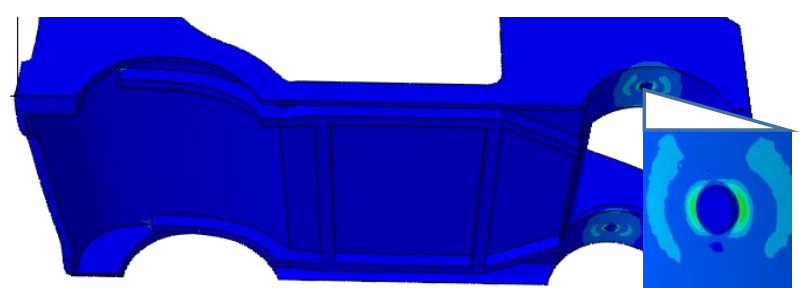

Gambar 4 sample hasil simulasi FEM chassis kasus 1 material aluminium AISI 6061.
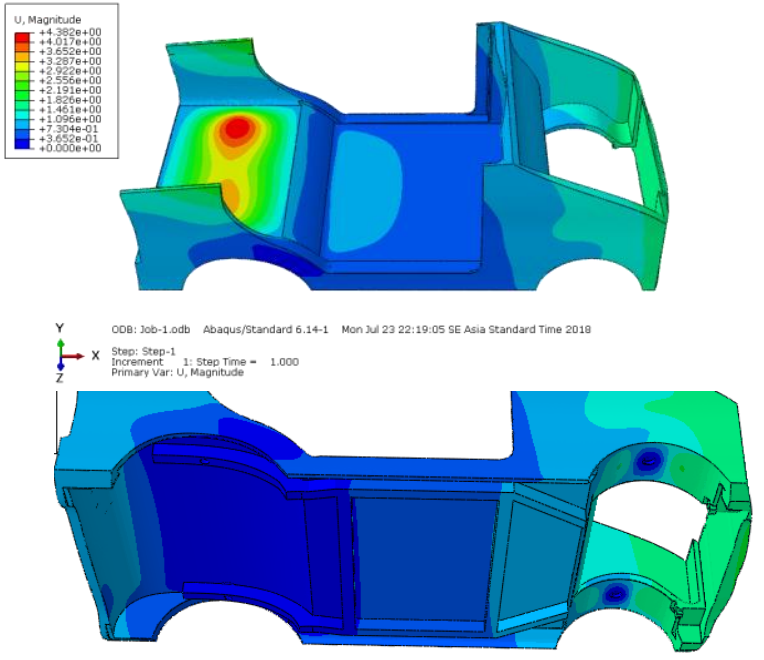

Gambar 4 merupakan hasil dari simulasi metode elemen hingga menggunakan aplikasi ABAQUS dengan material carbon fiber dan mendapatkan hasil tegangan von Mises yaitu 163,8 MPa dan displacement 4,38 mm. 

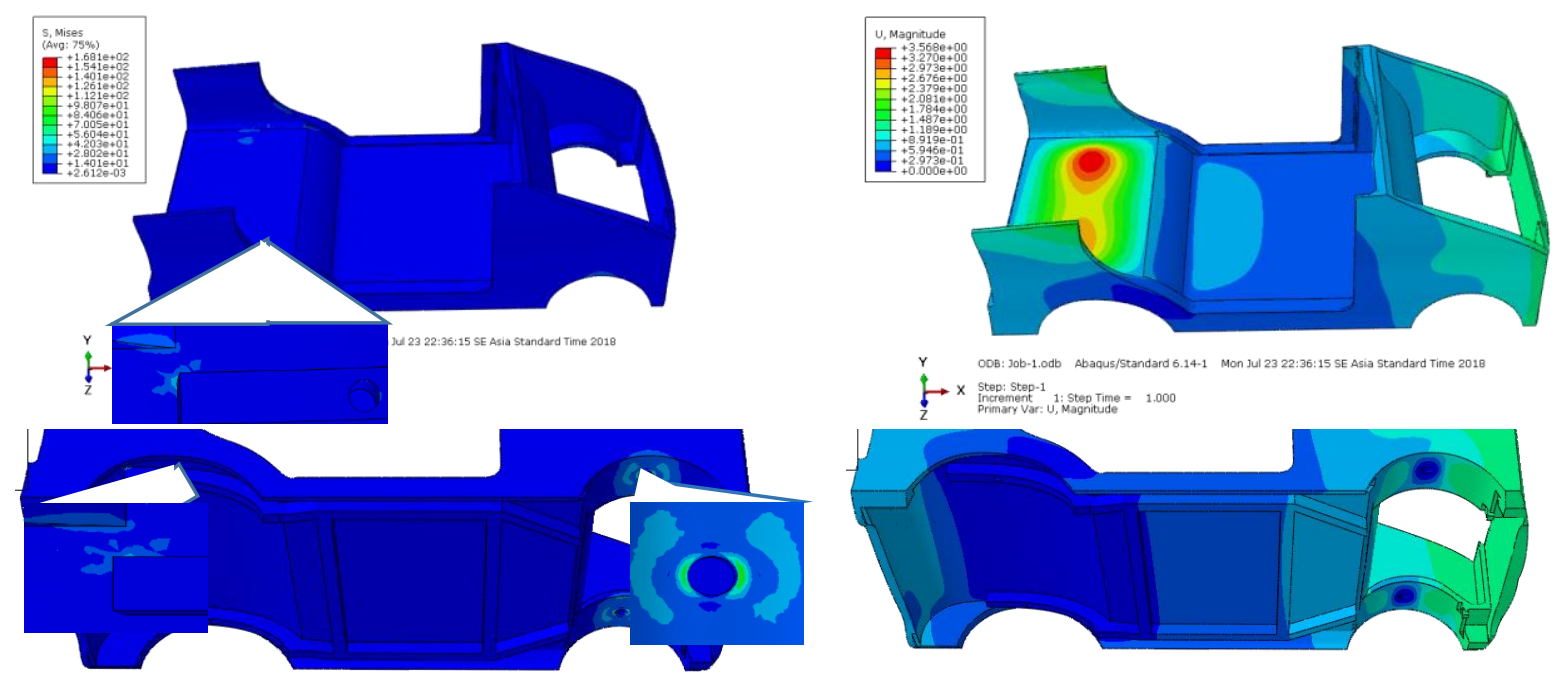

Gambar 5 sample hasil simulasi FEM chassis kasus 1 material carbon fiber.

Gambar 5 merupakan hasil dari simulasi metode elemen hingga menggunakan aplikasi ABAQUS dengan material carbon fiber dan mendapatkan hasil tegangan von Mises yaitu 168,11 MPa dan displacement 3,56 mm.
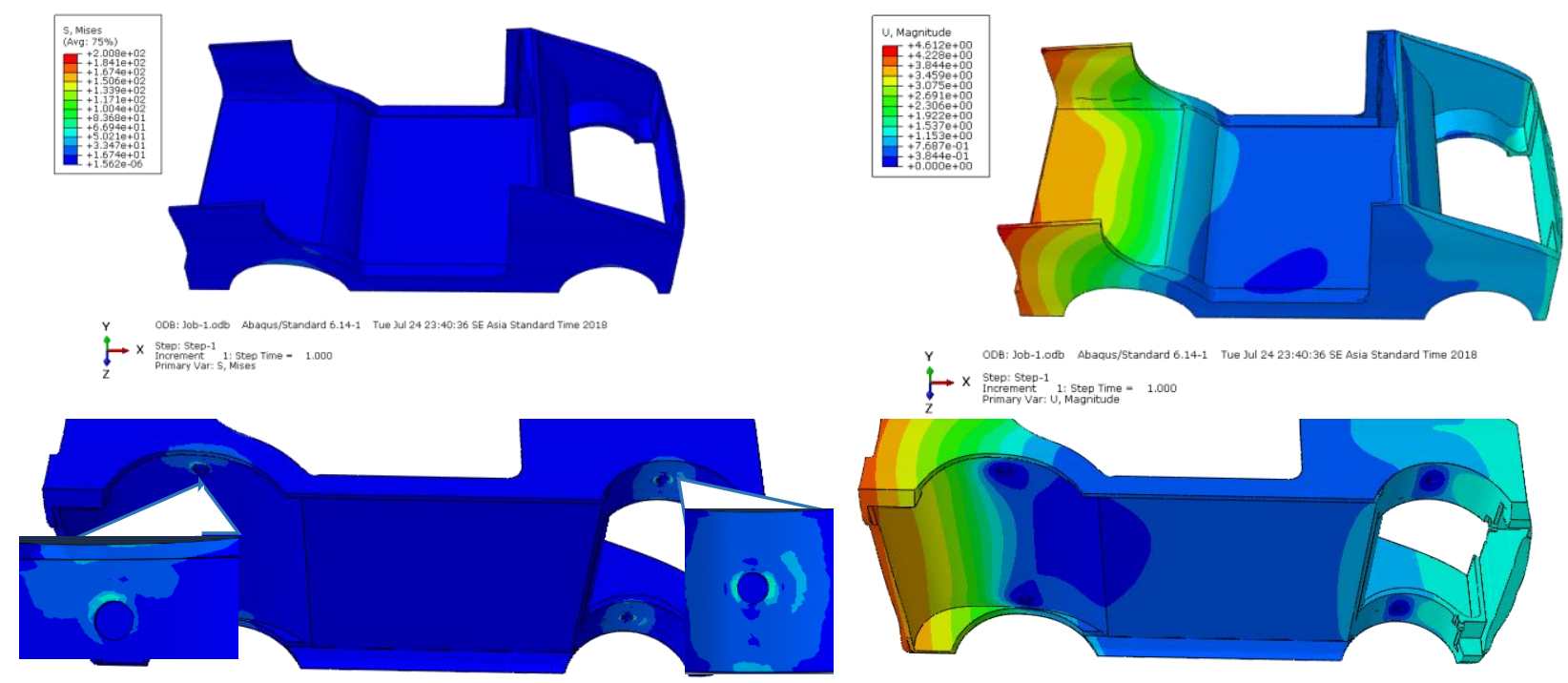

Gambar 6 sample hasil simulasi FEM chassis tanpa frame kasus 1 material carbon fiber.

Gambar 6 merupakan hasil dari simulasi metode elemen hingga menggunakan aplikasi ABAQUS dengan material carbon fiber dan mendapatkan hasil tegangan von Mises yaitu 200,82 MPa dan displacement 4,61 mm. Pada Tabel 5 menunjukkan tegangan von Mises dan displacement yang terjadi pada chassis mobil listrik Gentayu berdasarkan dari hasil simulasi yang telah dilakukan.

Tabel 5 Tegangan von Mises, displacement dan safety factor yang terjadi pada chassis.

\begin{tabular}{clccc}
\hline Kasus & Material & $\begin{array}{c}\text { Tegangan von Mises } \\
(\mathbf{M P a})\end{array}$ & $\begin{array}{c}\text { Displacement } \\
(\mathbf{m m})\end{array}$ & $\begin{array}{c}\text { Safety factor } \\
(\mathbf{M P a})\end{array}$ \\
\hline \multirow{2}{*}{ Kasus 1 } & Alloy steel & 165,61 & 3,76 & 1,5 \\
& Alumunium & 163,86 & 4,38 & 1,68 \\
& Carbon fiber & 168,11 & 3,56 & 2,43 \\
& Alloy steel & 121,77 & 4,98 & 2,1 \\
& Alumunium & 120,42 & 5,87 & 2,29 \\
Kasus 2 & Carbon fiber & 123,61 & 4,78 & 3,31 \\
& Alumunium & 193,15 & 5,83 & 1,42 \\
\hline
\end{tabular}




\section{Kesimpulan}

Hasil dari analisis tegangan von Mises tertinggi terdapat di material carbon fiber dengan nilai 200,82 MPa. Sedangkan tegangan von Mises terendah terdapat pada material aluminium AISI 6061 dengan nilai 120,42 MPa. Untuk displacement tertinggi terdapat pada material aluminium AISI 6061 dengan nilai 5,83 mm, sedangkan displacement terendah terdapat pada material carbon fiber dengan nilai 3,56 mm. Dari hasil simulasi chassis mobil listrik sebenarnya tanpa menggunakan frame, chassis masih sanggup menopang beban. Material carbon fiber lebih direkomendasikan, karena memiliki safety factor paling tinggi dibanding material alloy steel dan aluminium AISI 6061.

\section{Referensi}

[1] Frieske, B., Kloetzke, M., Mauser, F., 2013, “Trends In Vehicle Concept And Key Technology Development For Hybrid And Battery Electric Vehicles". In Electric Vehicle Symposium and Exhibition (EVS27).

[2] Faigle, E. M., 2000, "U.S. Patent No. 6,113,178". Patent and Trademark Office, Washington DC.

[3] Patil, H.B., Kachave, S.D., Deore, E.R., 2013, "Stress Analysis of Automotive Chassis with Various Thicknesses". IOSR Journal of Mechanical and Civil Engineering, 6(1), 44-49.

[4] Airale, A., Carello, M., Scattina, A., 2011, "Carbon Fiber Monocoque For A Hydrogen Prototype For Low Consumption Challenge". Materialwissenschaft und werkstofftechnik, 42(5), 386-392.

[5] Makhrojan, A., Budi, S.S., Jamari, J., Suprihadi, A., Ismail, R., 2015, "Strength Analysis of Monocoque Frame Construction In An Electric City Car Using Finite Element Method". In Electric Vehicular Technology and Industrial, Mechanical, Electrical and Chemical Engineering (ICEVT \& IMECE), 2015 Joint International Conference (pp. 275-279). IEEE.

[6] Makhrojan, A., Budi, S.S., Jamari, J., Suprihadi, A., Ismail, R., (2015, November). Strength analysis of monocoque frame construction in an electric city car using finite element method. In Electric Vehicular Technology and Industrial, Mechanical, Electrical and Chemical Engineering (ICEVT \& IMECE), 2015 Joint International Conference (pp. 275-279). IEEE.

[7] Budi, S.S., Suprihadi, A., Makhrojan, A., Ismail, R., Jamari, J. (2017, January). The effect of linear spring number at side load of McPherson suspension in electric city car. In AIP Conference Proceedings (Vol. 1788, No. 1, p. 030076). AIP Publishing.

[8] Setiyawan, T., Ismail, R., Bayuseno, A.P., (2018, June), Analysis of battery consumption of Gentayu electric car on different types of headlight. In AIP Conference Proceedings (Vol. 1977, No. 1, p. 060009). AIP Publishing.

[9] Rifano, R., Ivananda, M.A., Ismail, R., Prastawa, H., Bayuseno, A.P., (2018, June), Ergonomic analysis on driver seat of electric car and its comparison with Lcgc car seat. In AIP Conference Proceedings (Vol. 1977, No. 1, p. 020004). AIP Publishing.

[10] Kurdi, O., 2018, “Optimisasi Ketebalan Chassis Kendaraan untuk Pengurangan Konsumsi Bahan Bakar Minyak Menggunakan Metode Elemen Hingga”. Eksergi, 14(1).

[11] Reis, J.M.L.D., 2005, "Mechanical Characterization of Fiber Reinforced Polymer Concrete"., Materials Research, $8(3), 357-360$. 